\title{
Pharmacovigilance: Present scenario and future goals
}

\author{
AK Mohiuddin \\ Assistant Professor, Dept. of Pharmacy, World University of Bangladesh, Dhanmondi, Dhaka, Bangladesh
}

*Corresponding Author:

Email: trymohi@gmail.com

\begin{abstract}
Pharmacovigilance is the science and exercises related with social affair, acknowledgment, evaluation, checking, and balancing activity of untoward contacts with pharmaceutical things. Pharmacovigilance basically sheets wellbeing of medicine. Pharmacists have enter jobs in prosperity frameworks to guard up the sensible and use of medicine for they are cure authorities who are unequivocally arranged in this field. The viewpoint of drug store understudies on pharmacovigilance and ADR uncovering has also been analyzed with an expect to focus the need to enhance content related to ADR declaring and pharmacovigilance in student drug store instructive projects. All inclusive, in spite of the way that the activity of pharmacists inside national pharmacovigilance frameworks contrasts, it is particularly all around seen. Compromise of ADR declaring thoughts in guidance instructive modules, getting ready of pharmacists and intentional duty of pharmacists in ADR uncovering is basic in achieving the security targets and conservation of general prosperity. In like manner, these learning openings can be pacified through relentless master enhancement extends and invigorating theoretical and sensible data in student drug store instructive projects. Without satisfactorily recognizing and recognizing getting ready necessities of pharmacists and other human administrations specialists, the ability of national pharmacovigilance frameworks is likely not going to upgrade which may exchange off patient's wellbeing.
\end{abstract}

Keywords: Prevention, Monitoring, Pharmacists, ADR, Safety, Medicine.

\section{Introduction}

WHO portrayed pharmacovigilance as "the science and activities relating to the recognizable proof, examination, appreciation, and balancing activity of opposing effects or some other medicine related issue" It is a crucial and unclear bit of clinical research. Both clinical fundamentals wellbeing and post-exhibiting pharmacovigilance (consistently known as Post advancing investigations or Phase IV clinical starters) are basic all through the thing life cycle. With a sensibly high number recently noticeable drug withdrawals, both the pharmaceutical business and what's more extraordinary managerial workplaces over the globe have extended the bar. Early banner distinguishing proof from the post-promoting perception considers and clinical primers in beginning times have now been balanced by critical pharmaceutical associations in order to perceive the perils related with their helpful thing/s as appropriate on time as could be normal in light of the current situation. An ADR is portrayed by the WHO as "a harmful, startling effect of a medicine that occurs in bits consistently used in individuals for the end, prophylaxis and treatment of disease". The signs of ADRs depend upon the age, sex, innate, polypharmacy, parcel precision, and environmental and other inside factors like ailment conditions. ADRs customarily replied in as a result of known or cloud pharmacological features, poor thing quality (e.g., deluding, dirtied, misbranded, phony, unremarkable), solution botches in prescribing, preparing, managing, or taking the medicine which requires hospitalization, causing basic impair/inadequacy, sometimes risky and moreover death declared.

Incorporation: Pharmacovigilance is a procedure which incorporates:

1. The observing of utilization of therapeutic items in regular clinical practice, in order to have the capacity to recognize already undisclosed unfriendly responses or an adjustment in the idea of unfavorable responses.

2. Risk-advantage evaluation of restorative items, which picks what activity, if vital, is basic for a more secure utilization of therapeutic items.

3. Providing data to human services experts and additionally to patients so as to enhance the protected and powerful utilization of therapeutic items.

Wellsprings of Data in Pharmacovigilance: Pharmacovigilance utilizes data from numerous sources:

1. Natural detailing of unfavorable responses from medicinal services experts (connection to antagonistic responses)

2. Clinical preliminaries and epidemiological investigations

3. Published worldwide therapeutic writing

4. Pharmaceutical organizations

5. Healthcare and populace measurements

6. Information on the utilization of restorative items

\section{Types and Prevalence of ADRs}

ADRs in hospitalized patients can be parceled into two classes: those that are the explanation behind facility affirmation, and those that occur in the midst of hospitalization. There is confined data on ADRs, 
especially as for the reactions that occur after affirmation. It is assessed that ADRs occur in $10 \%$ of the general open and 10 to $20 \%$ of in-patients, past what $15 \%$ of these ADRs can be deadly. ${ }^{1,2}$ about $15 \%$ to $20 \%$ of ADRs identify with HDRs, which are activated by introduction to a medicine in a bit that is for the most part continued by strong individuals, and the reactions are grouped by target symptoms that can be duplicated subsequent to coming about representation. ${ }^{2}$ ADRs address a basic purpose behind horridness and are thought to cause some place in the scope of $10 \%$ and $30 \%$ of all mending focus affirmations in progressively settled patients. ${ }^{3}$ In USA, over $90 \%$ of adults developed multi-year and increasingly prepared use one remedy for consistently and $10 \%-25 \%$ experience a hostile drug reaction. ${ }^{4}$ These ADRs are in charge of 3-7\% of mending office affirmations. The prevalence of ADRs was more in female patients when stood out from men. ADRs by and large occurred in the age social affair of 41-50 years. ${ }^{5}$

\section{Methodology}

Research led an all year far reaching writing look, which included specialized bulletins, papers diaries, and numerous different sources. The present investigation was begun from the earliest starting point of 2018 . PubMed, ALTAVISTA, Embase, Scopus, Web of Science, and the Cochrane Central Register of was completely sought. The catchphrases were utilized to look for changed distributers' diaries like Elsevier, Springer, Willey Online Library, Wolters Kluwer were broadly pursued. Medicine and specialized specialists, pharma organization delegates, clinic attendants and physicists were given their profitable proposals. Forecasts depended on evaluations, for example, drug end clients, suppliers or prescribers, general learning of sane use, result and kinds of various occurrences of ADR and resistance, their administrations or ignoring. Studies with respect to consideration and data wellsprings of pharmacovigilance were given needs. A few factors that impact prescription taking conduct, rebelliousness, ADR announcing by pharmacists were collectively examined and added to the article. Issues in regards to monetary and social boundaries were observed to be not the same as subcontinents, nations and even states. Most critical highlights of pharmacist's job in remedial mediation were added a while later to keep up a coherent arrangement. Drug factors, ecological variables and supplier patient connection pursued by pharmacist's job in dealing with patients and to change or revision of prescription directing, apportioning, checking was included to uncover their impact patient consistence which is the inevitable objective of meeting remedial rules. Numerous investigations discovered in regards to pharmacists' job in restorative cost minimization, job in doctor's facility and other medicinal services settings, illness counteractive action and way of life the board observed to be not inside the extent of this article.

\section{The Value of Patient Reporting}

Patient announcing includes new data, and point of view about ADRs in a way generally inaccessible. This can add to better decision-making techniques in administrative exercises in the EU, there were 48,782 patient reports in 2015, showing an expansion of $30 \%$ on 2014. ${ }^{6}$ Most patients didn't know about detailing frameworks and others were befuddled about announcing. Patients were fundamentally propelled to make their ADRs known to turn away comparative enduring in different patients. By expanding patient associate and giving clear announcing procedures, revealing frameworks could more readily achieve patient detailing of ADRs. The WHO screens indiscreet ADR detailing in the greater part of nations. A typical issue is under-reporting. It is anticipated that just 5$10 \%$ of ADRs are accounted for. In spite of the fact that there is no gauge of patient revealing, 95\% of HCPs don't report ADRs. In 1976, a British doctor, Inman, was the first to distribute explanations behind underreporting by HCPs, including:

1. Contentment (believing that serious ADRs are well documented when the drug is released on the market)

2. Fear of being involved in a lawsuit

3. Guilt for having been responsible for damage observed in a patient

4. Ambition to publish a case series or financial benefit

5. Lack of awareness of the notification process

6. Insecurity about reporting suspicions of an ADR

7. Indifference ${ }^{7}$

\section{The Value of Healthcare Professionals' Reporting:} The information collected during the premarketing phase is incomplete with regard to adverse drug reactions and this is mainly because

1. Patients used in clinical trials are limited in number and are not illustrative to the public at large. In addition, the conditions of use of medicines differ from those in clinical practice and the period is limited.

2. Information about rare but serious untoward reactions, chronic toxicity, and use in special groups (such as children, the elderly, or pregnant women) or drug interactions is often incomplete.

Thus, post-displaying observation is basic to permit area of less typical yet sometimes extreme ADRs. It is indispensable to permit area of less ordinary, yet now and again serious ADRs. Prosperity specialists worldwide should give a record of ADRs as it can save presences of their patients and others. ${ }^{8}$ Banner disclosure is important to perceive the medicine related antagonistic effects. In any case, the amount of reports sent to national pharmacovigilance centers is fundamental and furthermore the idea of reports. The 
idea of reports is irrefutably transcendent when they are filled by prosperity specialists who have pharmacology data, i.e. pharmacists, pros, therapeutic orderlies, specialist partners, dental masters, etc. It will be by a long shot prevalent if it might be chronicled and recovered from drug store information frameworks.

\section{Factors of ADR Reporting}

ADRs have risen as a significant clinical and general restorative issue in charge of around 5 to $35 \%$ of recuperating focus affirmations in both made and making countries. In the US and EU, ADRs are among the primary ten explanations behind short life and moreover rising the cost of thought. Quick uncovering of ADRs to cure authoritative bodies is a basic medicine security check yet under-itemizing is a critical test even in made countries with palatable human and material resources for confront the issue ${ }^{9}$ Factors that may add to underreporting among HCPs fuse learning, inconsiderateness, nonappearance of time and drive. Nonattendance of organized uncovering methodology and openings in human administrations information frameworks moreover causes underreporting. ${ }^{10}$ concentrates recorded ADEs in diagrams to help dauntlessness of thought anyway never declared them to outside associations. Providers stood up to time goals, and itemizing would have required duplication of documentation. ${ }^{11}$ Audits of human administrations providers in serious recuperating focuses have found that therapeutic guardians will undoubtedly report scenes than masters and that there are distinctive nuances for staff not uncovering, including not understanding how to report occasions, time constraints, helplessness about what to report, the longing for blame or discipline, and a wisdom that specifying events does not result in improvements. ${ }^{12}$

\section{Biological Medicines Pose Specific Challenges for Pharmacovigilance}

A continuous standard appropriated by the EMA focuses four key examinations for the pharmacovigilance of biologicals; specifically, immunogenicity, creating variance, strength/nippy chain necessities and thing perceptibility. Natural medicines are basically factor and but particular bundles of the proportionate characteristic medicine are not alike, the nature of each bunch is solidly controlled to ensure the wellbeing and ampleness of the medicine. Regardless, required gathering process changes can influence quality attributes of the natural and this can happen unbeknownst to restorative administrations specialists and patients. In exceptional cases, these movements can influence the immunogenicity of a thing. Regular medicines including biosimilars are winding up legitimately available. Biosimilars are obvious from the generics of manufactured medicines as, owing to the inconveniences of regular substances and their gathering frames, biosimilars are not absolutely undefined to the principal medicine on which they are based (reference medicine). Resemblance to the reference medicine is set up through an exhaustive identicalness practice guided at the quality, pre-clinical and clinical measurements. All as of late attested common medicines, including biosimilars, are obligated to furthermore checking for a period of 5 years after underwriting. ${ }^{10}$

\section{Medical and Economical Burden of ADRs}

Helpful load of FADRs is critical. The most basic concerns are suggested medicines, oversight of basic treatment, powerlessness to screen treatment and poor frameworks. These were related to flaws in guidance or getting ready, nonattendance of clear guidelines or traditions and failure to innovation existing tenets, among various reasons. ${ }^{13}$ A normal 106,000 passings communicated some place in the scope of 1966 and 1996 in US. In any case it is assessed that only 6\% of ADRs are represented. ${ }^{2}$ Likewise, half $70 \%$ are acknowledged avoidable. A foreseen 197,000 passings for every year in the EU are caused by ADRs and the total cost to society of ADRs in the EU is $€ 79$ billion. ADRs epitomize the fifth most normal explanation behind death in recuperating focus setting. ${ }^{14}$ In seriously wiped out adults, heavenly verification shows that liberal oxygen treatment grows mortality without upgrading other patient-basic outcomes. ${ }^{15}$ Some place in the scope of 1976 and 2007, 28 drugs were pulled once again from the US publicize for wellbeing reasons ${ }^{16}$ Passing rates due to ADRs are assessed from $0.1-2.9 \%$. A savvy eight-year (1999-2006) analyze drove in the US of $>2$ million passing's revealed that 2341 demise $(0.1$ per 100,000) were ADR-related passings. In 2005, drugs were the principle wellspring of death assessed at 739,936 consistently. ${ }^{17}$ The foreseen total cash related cost of $\$ 17.88$ billion addresses $1.55 \%$ of Australian aggregate national yield $^{18}$

\section{Pharmacovigilance in Healthcare Education}

Social protection specialists have little insight of pharmacovigilance and ADR uncovering, and simply couple of informative affiliations impacts influenced this care. Future human administrations providers should thusly get an adequate game plan of pharmacovigilance abilities to ordinarily suggest, circle, and screen drugs. Foreseeing, diagnosing, administering, and specifying ADRs are a basic bit of typical and safe suggesting and are acclimatized into different steps of the WHO-six-advance Guide to Good Prescribing. ${ }^{19}$ Different examinations have conveyed stress over the nonattendance of restorative administrations capable abilities in pharmacovigilance..$^{20,21}$ This nonappearance of student guidance and getting ready in pharmacovigilance is unsurprising with the low component of data, capacities, and exercises found in specialists and in 
practicing pharmacists, dental experts, and therapeutic orderlies $^{22-24}$ Originality to pharmacovigilance, a low element of ADR-enumerating capacities, a nonattendance of learning joined with negative manners like neglectfulness, fear authentic hazard, and nonappearance of importance are accepted to be related to the current insufficient response to various ADRs. ${ }^{25-}$ 28 A couple of interventions (completing traditions, enlightening workshops, or kept informing or telephone calls) have been executed attempting to upgrade the wellness of social protection specialists ${ }^{29-32}$ yet these medications are extravagant or disregard to convey clinically relevant and whole deal impacts. ${ }^{23}$

\section{Pharmacovigilance in Pharmaceutical Industries}

The aims of pharmacovigilance within the industry are essentially the same as those of regulatory agencies; that is to protect patients from unnecessary harm by identifying previously unrecognized drug hazards, elucidating pre-disposing factors, refuting false safety signals and quantifying risk in relation to benefit. Although the perspectives of companies and the regulatory agencies may be different, they now work more and more closely together and share information. ${ }^{33}$

\section{Worldwide Monitoring of Pharmacovigilance}

In 2002, in excess of 65 nations have their own pharmacovigilance focuses. Enrollment of the WHO for International Drug Monitoring is facilitated by the WHO Collaborating Center for International Drug Monitoring, known as the UMC. Pharmacovigilance is presently solidly dependent on sound logical standards and is basic to successful clinical practice. The order needs to grow further to meet open desires and the requests of current general wellbeing. A mind boggling and indispensable relationship exists between wide scopes of accomplices in the act of medication safety checking.

The Quality Assurance and Safety: The group is a piece of the Department of Essential Drugs and Medicines Policy, inside the WHO Health Technology and Pharmaceuticals bunch. ${ }^{34}$

UMC, Sweden: A free, not-revenue driven establishment a middle for universal logical research, situated in Sweden - firmly related with WHO, since 1978. The chief capacity of the UMC is to deal with the universal database of ADR reports got from National Centers. 35

The National Pharmacovigilance Centers: National Centers have assumed a vital job in expanding open attention to tranquilize safety. This advancement is somewhat owing to the way that numerous national and local focuses are housed inside doctor's facilities, restorative schools or toxic substance and medication data focuses, as opposed to inside the points of confinement of a medication administrative expert. ${ }^{36}$
Hospitals: various medicinal foundations have progressed ADRs and drug blunder close watch frameworks in their centers, wards and crisis rooms.

Academia: Academic focuses of pharmacology and drug store have assumed a vital job through instructing, preparing, look into, strategy improvement, clinical research, morals councils (institutional survey sheets) and the clinical administrations they give. ${ }^{37}$

Health Professionals: Originally doctors were the main experts welcomed to report as making a decision about whether sickness or medicine causes a specific side effect by practicing the aptitude of differential determination. ${ }^{38}$

Patients: Only a patient knows the genuine advantage and mischief of a medicine taken. Coordinate patient investment in the revealing of medication related issues will build the proficiency of the pharmacovigilance framework and make up for a portion of the inadequacies of frameworks dependent on reports from wellbeing experts as it were.

\section{Necessity of Collaboration}

Pharmacovigilance framework usage is the need which is conceivable by joint effort between the scholarly world, human services suppliers including pharmacist, patient, maker, government, media, and common society, UMC Sweden working under (WHO), FDA, ISOP and other worldwide association taking a shot at medication safety ${ }^{39}$ There are five WHO Collaborating Centers working for pharmacovigilance, each in pro regions. Notwithstanding UMC in Sweden, these are in India, Morocco, the Netherlands, and Norway.

The focus in Rabat (Morocco): Became a WHO Collaborating Center in 2011. The Rabat focus underpins WHO by building limit in the WHO Eastern Mediterranean Region, in francophone, and Arabic nations.

Pharmacovigilance Center Lareb (Netherlands): Netherlands' national pharmacovigilance community for Pharmacovigilance in Education and Patient Reporting. It turned into a WHO Collaborating Center in 2013.

The Center in Norway was built up in 1982 in Oslo at the Department of Pharmacoepidemiology at the Norwegian Institute of Public Health, sponsored by the Norwegian Government.

Founded in 2010, the PvPI was assigned as an expert focus by WHO in Geneva, 2017.40,41

\section{Role of Pharmacist in the Management of ADRs}

1. In the United States alone, DDIs add to $20 \%$ everything being equal, which cause about 770,000 passings and result in $\$ 30$ billion to $\$ 180$ billion in human services costs and four hospitalizations for every 1,000 individuals yearly. A pharmacist assumes a pivotal job in the distinguishing proof, location, counteractive action, and the board of 
DDIs, sedate sustenance collaborations and $\mathrm{ADRs}^{42,43}$ Pharmacist can complete such exercises in inpatient setting, while at the same time partaking in survey diagrams amid ward rounds, and amid drug the executives while managing solutions.

2. The prevalence of patients who visited different healing facilities with the equivalent or comparable condition was about $40 \%$ among patients going to government outpatient divisions in Hong Kong, $23 \%$ among essential consideration patients in Japan, and $23.5 \%$ among outpatients in Taiwan ${ }^{44}$ Patients who get restorative consideration from various human services suppliers, especially from various healing centers, are bound to endure ADRs. A few scientists suggested that pharmacists use mechanized screening programming to distinguish potential medication treatment issues and avert unfavorable occasions. Others proposed utilization of CPOE with CDS to recoup medicine mistakes.

3. The intercession of pharmacists by sorting out addresses and gathering dialogs in this way giving data about the significance, earnestness, preventability and stipulation of revealing shows increased enhancement of learning, demeanor and discernment about ADRs.

4. All wellbeing experts assume their particular jobs in adjusting among advantages and dangers of prescription when it is presented in the market. Be that as it may, the aptitude of a pharmacist about a medication, particularly if recently advertised, assume a progressively huge job in ADRs answering to the experts which helps in either withdrawing the item from the market or cause naming changes ${ }^{45}$. Following Thalidomide-Induced Phocomelia catastrophe, Bowles asked ADR revealing as a factor in underwriting of pharmacists in $1964 .{ }^{46}$

5. Pharmacists working in network drug store have an additional advantage of distinguishing and revealing $\mathrm{ADRs}$ while managing on the counter medicines and natural items. In a network drug store, a pharmacist might not have immediate and unmistakable patient rundown but rather the patients going to a similar drug store to refill their remedy offers the pharmacist a chance to identify a conceivable ADR that the patient may understanding and can help in the administration and the detailing of the said ADR. Pharmacist conference aptitudes should be assessed if MURs are to understand their imagined points ${ }^{47}$

\section{Role of Pharmacist in Pharmacovigilance}

The responsibility of the pharmacist to pharmacovigilance should, in any case, not be limited to ADR reporting. Especially, recuperating office pharmacists can expect an enormous activity in ADR declaring in light of the fact that the most real opposing medicine events occur in specialist's offices and ADRs speak to a critical degree of specialist's office affirmations. ${ }^{48}$ The pharmacist could be a coordinator between different people from social protection gathering and the patients, to ensure both watchfulness and consistence. Thusly, support of pharmacists in prosperity the officials framework is winding up to a great degree essential well ordered. Pharmacists are related with passing on social protection workplaces and also proposing restorative staff on genuine accumulation of drugs. They furthermore plan, screen and survey sedate undertakings to update prosperity and lessen prosperity abberations. ${ }^{49,50}$ Recuperating office pharmacists ensure that medicines are administered safely and enough with the objective that they are appropriate for the age, sex, body weight and clinical status of the patient. System pharmacists of course come in direct contact with the all-inclusive community and they distribute drugs and additionally direction's patients seeing general prosperity topics, for instance, diet, work out, drive the officials, over-the-counter medicines etc. ${ }^{51,52}$ A few social order pharmacists moreover outfit explicit organizations to help patients with diabetes, asthma, smoking suspension, constant drug use, and patients with hypertension. The activity of pharmacists in pharmacovigilance frameworks is extended under Affordable Care Act or the present social protection change, since people who by and large had no assurance, by and by meet all prerequisites for security; and this could assemble the case for drug store organizations. More pharmacists will be required in passing on prosperity preparing, including guidance on DDIs. ${ }^{53}$ Pharmacists can thwart quiet affiliation, guide patient regarding the disorder and medicine e.g. giving information, direction and support about medicine and treatment in light of their passage of social correspondence. The changing activity of the pharmacist from customary 'sedate contraption' thought towards 'pharmaceutical thought provider' broadened the activity of pharmacists. Along these lines, pharmacists can expect a key occupation in redirecting drug abuse by giving clear information about the adversarial effects of remedies. ${ }^{54}$ Besides, the headway of electronic information frameworks has been a historic in recognizing and intervening drug related issues, for instance, portion, antagonistic reactions, affiliations, consistence or insufficiency.

\section{Conclusion}

Being drug ace and mentor of shielded and convincing prescription use, pharmacists have basic imagine in recognizable proof, report, seeing nearby evasion of ADRs. The nonattendance of uneasiness still exists among pharmacists who are limited to change from thing arranged to patient orchestrated. The opening can be restricted through continued with master enhancement programs and also strengthening data base in student level. A fortifying and duty of 
system pharmacists to patient record check and electronic declaring may similarly decrease ADR related events. Without fruitful distinctive confirmation and fulfillment of planning needs of pharmacists and other restorative administrations specialists, the viability of national pharmacovigilance frameworks is presumably not going to improve, which may deal patient security. To accomplish this goal, managerial bodies should make authorizations to awaken pharmacists to be viably drawn in with the framework. Other than their dynamic participation, their allotted work should have an increasingly broad range to gain the best help reliant on their bent. Convincing usage of pharmacists' workforce will improve the aftereffect of the pharmacotherapy and what's more decrease overall prosperity costs.

\section{Acknowledgement}

It's a phenomenal gratefulness and regard to be a bit of social protection research and preparing. Pharmacists of all trains that I have driven was particularly helpful in discussing pharmacovigilance situation in home and abroad, giving books, journals, announcements and significant time. The best help was from my understudies who paid energy for my subject as class deliver and encouraged to form such article including ADR the board and pharmacovigilance. Despite an exceptional lack of sponsoring this reason from any master, the experience was adequate to proceed ask about.

Purpose of the study: Discussion and projection of present situation analysis and future demand of pharmacovigilance. The pharmacists have a vital role to play which is thoroughly discussed.

Findings: Pharmacists are indispensable piece of social insurance the executives framework and significance of their pretend isn't after specialists and medical caretakers. Any future job for the pharmacist in guiding, checking and watchfulness could be tended to as a component of a formalized, vital way to deal with making a coordinated human services group, with consideration regarding further upgrade of pharmacovigilance in any nation, network or a social insurance setting.

Research Limitations: Research has the significant constraint with managing too numerous data on pharmacovigilance around the world. Just essential part of extended job of pharmacists, current circumstance of cautiousness in various nations and a couple of future prospect, request and arrangements of pharmacists in taking care of those developing requests are talked about.

Practical Implication: The spirit of this article was to insight concerning current circumstance and future requests of pharmacovigilance. Alongside understudies, analysts and experts of various foundation and controls, e.g. Pharmacists, advertisers, specialists, medical caretakers, doctor's facility experts, open agents, strategy creators and administrative specialists need to procure much from this article.

Social Implication: The article ought to contribute a coordinated rule for patient consistence, request pharmacovigilance and last yet not the minimum a gleaming coating of better medicinal services circumstance in not so distant future.

Abbreviations: Computerized Provider Order Entry (CPOE); Clinical Decision Support (CDS); Drug-Drug Interactions (DDIs); Healthcare Professionals (HCPs); Hypersensitivity Drug Reactions (HDRs); European Medicines Agency (EMA); Fatal Adverse Drug Reactions (FADRs); Medicines Use Review (MUR); Uppsala Monitoring Centre (UMC); International Society of Pharmacovigilance (ISOP); Pharmacovigilance Program of India (PvPI).

\section{References}

1. Öztürk AB, Özyiğit LP, Şener Ü, et al. Reporting Adverse Drug Reactions in a Tertiary Care Hospital in İstanbul. Turk Thorac J. 2018;19(4):237-39.

2. Ribeiro MR, Motta AA, Marcondes-Fonseca LA, KalilFilho J, Giavina-Bianchi P. Increase of $10 \%$ in the Rate of Adverse Drug Reactions for Each Drug Administered in Hospitalized Patients. Clinics (Sao Paulo). 2018;73:185.

3. Parameswaran Nair N, Chalmers L, Peterson GM, Bereznicki BJ, Castelino RL, Bereznicki LR. Hospitalization in older patients due to adverse drug reactions -the need for a prediction tool. Clin Interv Aging. 2016;11:497-505. Published 2016 May 2. doi:10.2147/CIA.S99097

4. Ruscin JM, Linnebur SA. Aging and Drugs. Merck Manual Consumer Version. (C) 2018 Merck Sharp \& Dohme Corp., a subsidiary of Merck \& Co., Inc., Kenilworth, NJ, USA

5. Chopra D, Rehan HS, Sharma V, Mishra R Chemotherapy-induced adverse drug reactions in oncology patients: A prospective observational survey. Indian J Med Paediatr Oncol. 2016;37(1):42-66. doi: 10.4103/0971-5851.177015. PubMed PMID: 27051157

6. Inácio P, Cavaco A, Airaksinen M. The value of patient reporting to the pharmacovigilance system: a systematic review. Br J Clin Pharmacol. 2016;83(2):227-46.

7. Al Dweik R, Stacey D, Kohen D, Yaya S. Factors affecting patient reporting of adverse drug reactions: a systematic review. Br J Clin Pharmacol. 2016;83(4):87583.

8. Gurmesa LT, Dedefo MG. Factors Affecting Adverse Drug Reaction Reporting of Healthcare Professionals and Their Knowledge, Attitude, and Practice towards ADR Reporting in Nekemte Town, West Ethiopia. Biomed Res Int. 2016;2016:5728462.

9. Avong YK, Jatau B, Gurumnaan R, et al. Addressing the under-reporting of adverse drug reactions in public health programs controlling HIV/AIDS, Tuberculosis and Malaria: A prospective cohort study. PLoS One. 2018;13(8):200810. Published 2018 Aug 22. doi:10.1371/journal.pone.0200810

10. O'Callaghan J, Griffin BT, Morris JM, Bermingham M. Knowledge of Adverse Drug Reaction Reporting and the Pharmacovigilance of Biological Medicines: A Survey of Healthcare Professionals in Ireland. Bio Drugs. 2018;32(3):267-80. 
11. Hohl CM, Small SS, Peddie D, Badke K, Bailey C, Balka E. Why Clinicians Don't Report Adverse Drug Events: Qualitative Study. JMIR Public Health Surveill. 2018;4(1):21. Published 2018 Feb 27. doi:10.2196/publichealth.9282

12. Gifford ML, Anderson JE. Barriers and motivating factors in reporting incidents of assault in mental health care. J Am Psychiatr Nurses Assoc. 2010;16(5):288-98. doi: 10.1177/1078390310384862. PubMed PMID: 21659279.

13. Ferner RE, Easton C, Cox AR. Deaths from Medicines: A Systematic Analysis of Coroners' Reports to Prevent Future Deaths. Drug Saf. 2018;41(1):103-10. doi: 10.1007/s40264-017-0588-0. PubMed PMID: 28808959

14. Giardina C, Cutroneo PM, Mocciaro E, et al. Adverse Drug Reactions in Hospitalized Patients: Results of the FORWARD (Facilitation of Reporting in Hospital Ward) Study. Front Pharmacol. 2018;9:350. Published 2018 Apr 11. doi:10.3389/fphar.2018.00350

15. Chu DK, Kim LH, Young PJ, Zamiri N, Almenawer SA, Jaeschke R, Szczeklik W, Schünemann HJ, Neary JD, Alhazzani W. Mortality and morbidity in acutely ill adults treated with liberal versus conservative oxygen therapy (IOTA): a systematic review and meta-analysis. Lancet. 2018;28;391(10131):1693-705. doi: 10.1016/S0140-6736(18)30479-73. Epub 2018 Apr 26. Review. PubMed PMID:29726345.

16. Wilke RA, Lin DW, Roden DM, et al. Identifying genetic risk factors for serious adverse drug reactions: current progress and challenges. Nat Rev Drug Discov. 2007;6(11):904-16.

17. Angiji A. Adverse Drug Reactions related to mortality and morbidity: Drug - drug interactions and overdoses. Available From:

http://www.xendo.com/images/pdf/ADRs-by-Majorsystems-II-Final-Report.pdf

18. Hillman D, Mitchell S, Streatfeild J, Burns C, Bruck D, Pezzullo L. The economic cost of inadequate sleep. Sleep. 2018;1;41(8). doi: 10.1093/sleep/zsy083. PubMed PMID: 29868785 .

19. Hartman J, Härmark L, van Puijenbroek E. A global view of undergraduate education in pharmacovigilance. Eur J Clin Pharmacol. 2017;73:891-99. doi: 10.1007/s00228017-2237-z.

20. Abubakar AR, Haque M. Pharmacovigilance practice: the current challenges and the gaps in the medical students' curriculum. J App Pharm Sci. 2016;6(5):210-15. doi: 10.7324/JAPS.2016.60532.

21. Gavaza P, Bui B. Pharmacy students' attitudes toward reporting serious adverse drug events. Am J Pharm Educ. 2012;76(10):194. doi: 10.5688/ajpe7610194.

22. De Angelis A, Colaceci S, Giusti A, Vellone E, Alvaro R. Factors that condition the spontaneous reporting of adverse drug reactions among nurses: an integrative review. J Nurs Manag. 2015;23(4):1-13.

23. Pagotto C, Varallo F, Mastroianni P. Impact of educational interventions on adverse drug events reporting. Int J Technol Assess Health Care. 2013;29(4):410-417. doi: 10.1017/S0266462313000457.

24. Rutter P, Brown D, Howard J, Randall C. Pharmacists in pharmacovigilance: can increased diagnostic opportunity in community settings translate to better vigilance? Drug Saf. 2014;37(7):465-69. doi: 10.1007/s40264-014-01916.

25. Gonzalez-Gonzalez C, Lopez-Gonzalez E, Herdeiro MT, Figueiras A. Strategies to improve adverse drug reaction reporting: a critical and systematic review. Drug Saf. 2013;36(5):317-28. doi: 10.1007/s40264-013-0058-2.
26. Lopez-Gonzalez E, Herdeiro MT, Figueiras A. Determinants of under-reporting of adverse drug reactions: a systematic review. Drug Saf. 2009;32(1):1931. doi: 10.2165/00002018-200932010-00002.

27. WH I Attitudes to adverse drug reaction reporting. $B r J$ Clin Pharmacol. 1996;41(5):434-35.

28. Alessia De Angelis SC, Giusti A, Vellone E, Alvaro R. Factors that condition the spontaneous reporting of adverse drug reactions among nurses: an integrative review. J Nurs Manag. 2015;24(2).

29. Herdeiro MT, Ribeiro-Vaz I, Ferreira M, Polnia J, Falco A, Figueiras A. Workshop-and telephone-based interventions to improve adverse drug reaction reporting: a cluster-randomized trial in Portugal. Drug Saf. 2012;35(8):655-65. doi: 10.1007/BF03261962.

30. Johansson-Pajala RM, Martin L, Fastbom J, Blomgren KJ. Nurses' self-reported medication competence in relation to their pharmacovigilant activities in clinical practice. J Eval Clin Pract. 2015;21(1):145-52. doi: 10.1111/jep.12263.

31. Ribeiro-Vaz I, Santos CC, Cruz-Correia R. Promoting adverse drug reaction reporting: comparison of different approaches. Rev Saude Publica. 2016;50:14. doi: 10.1590/S1518-8787.2016050006122.

32. Ribeiro-Vaz IH, T M, Polonia J, Figueiras A. Strategies to increase the sensitivity of pharmacovigilance in Portugal. Rev Saude Publica. 2011;45(1):129-35. doi: 10.1590/S0034-89102010005000050.

33. Talbot JC, Nilsson BS. Pharmacovigilance in the pharmaceutical industry. Br J Clin Pharmacol. 1998;45(5):427-31.

34. WHO Medicines Strategy: Framework for Action in Essential Drugs and Medicines Policy 2000-2003.

35. Olsson S. The role of the WHO Programme for International Drug Monitoring in coordinating worldwide drug safety efforts. Drug Saf. 1998;19:1-10.

36. Coulter DM. The New Zealand intensive medicines monitoring programme in proactive safety surveillance. Pharmacoepidemiol Drug Saf. 2000;9:273-80.

37. Moore N. The role of the clinical pharmacologist in the management of ADRs. Drug Saf. 2001;24:1-7.

38. Hornbuckle K, Wu HH, Fung MC. Evaluation of spontaneous adverse event reports by primary reporter: A 15-year review (1983 to 1997) Drug Inf J. 1999;33:111724.

39. Mahmood KT, Amin F, Tahir M, Haq IUl. Pharmacovigilance - a need for best patient care in Pakistan. A review. Pharm Sci Res. 2011;3(11):1566-84.

40. Uppsala Monitoring Centre (UMC) Web. WHO Collaborating Centres. 2017.

41. WHO Web. The Importance of Pharmacovigilance Safety Monitoring of Medicinal Products. 2002. Essential Medicines and Health Products Information Portal A World Health Organization resource.

42. Peabody J, Acelajado MC, Robert T, et al. Drug-Drug Interaction Assessment and Identification in the Primary Care Setting. J Clin Med Res. 2018;10(11):806-14.

43. Ansari J. Drug interaction and pharmacist. J Young Pharm. 2010;2(3):326-31.

44. Yeh YT, Hsu MH, Chen CY, Lo YS, Liu CT. Detection of potential drug-drug interactions for outpatients across hospitals. Int J Environ Res Public Health. 2014;11(2):1369-83. Published 2014 Jan 27. doi:10.3390/ijerph110201369

45. Shah RR. Importance of Publishing Adverse Drug Reaction Case Reports: Promoting Public Health and Advancing Pharmacology and Therapeutics. Drug Saf 
Case Rep. 2017;4(1):11. Published 2017 Sep 20. doi:10.1007/s40800-017-0053-0

46. Bowles GC., Jr Adverse drug reaction reporting urged as factor in accreditation. Mod Hosp. 1964;103:20.

47. Latif A, Helen P, Boardmana F. The contribution of the Medicines Use Review (MUR) consultation to counseling practice in community pharmacies. Patient Education and Counseling. 2011;83(3):336-44. https://doi.org/10.1016/j.pec.2011.05.007

48. van Grootheest AC, de Jong-van den Berg LT. The role of hospital and community pharmacists in pharmacovigilance. Res Social Adm Pharm. 2005;(1):126-33. Review. PubMed PMID: 17138470.

49. APhA. Principles of Practice for Pharmaceutical Care. (C) Copyright 2018, American Pharmacists Association. Available From: https://www.pharmacist.com/principlespractice-pharmaceutical-care

50. Mohiuddin AK, Patient Compliance: An Untold Story or a Fairy Tale? Pharmaceut Reg Affairs 2018;7:207. doi: 10.4172/2167-7689.1000207

51. Brajesh Kumar et al. / Professional scopes and roles of community pharmacists in various health care services: An updated review. Journal of Pharmacy Research. 2011,4(5),1331-35.

52. Bhaskaran S. A vision of Indian pharmacist in 2020. PHARMABIZ.com 2010.

53. Toklu HZ, Mensah E. Why do we need pharmacists in pharmacovigilance systems?. Online J Public Health Inform. 2016;8(2):193. Published 2016 Sep 15. doi:10.5210/ojphi.v8i2.6802

54. Management Sciences for Health (www.msh.org). chapter 33. Encouraging appropriate medicine use by consumers. Available From: https://www.msh.org/sites/msh.org/files/mds3-ch33consumeruse-mar2012.pdf 